\title{
Impact of brine on the marine environment and how it can be reduced
}

\author{
Yolanda Fernández-Torquemada(1), Adoración Carratalá(2), and José Luis Sánchez \\ Lizaso(1)
}

(1) Department of Marine Sciences and Applied Biology, University of Alicante, P.O. Box 99; E-03080. Alicante (Spain). E-mail: Yolanda.Fernandez@ua.es, Jl.sanchez@ua.es

(2) Department of Chemical Engineering, University of Alicante, P.O. Box 99; E-03080. Alicante (Spain). E-mail: A.carratala@ua.es

\begin{abstract}
Seawater desalination is a potential solution for addressing water shortages. The number of desalination plants projected and constructed in some regions has substantially increased in recent decades. However, desalination process poses some undesirable environmental impacts in terms of energy consumption, land use, and seawater intake, but particularly the most significant impacts are related with effluent disposal and discharge. Thus, the challenge for the desalination industry is to produce new water resources without increasing pressure on the marine environment. The effluent characteristics depend on the feed water and desalination technology used. Negative environmental impacts of brine discharge from a desalination plant can be minimized by appropriate planning. The countermeasures should vary depending on plant size and type, the biological communities in the discharge area, and the area's hydrogeological features. This study overviews the available information about minimizing the harmful effects of the desalination industry. It highlights that an appropriate discharge location must be selected and the mixing of brine with ambient seawater must be maximized to reduce the environmental impacts of brine. Moreover, it is helpful to establish a carefully designed environmental monitoring program to assess brine plume distribution over time while monitoring biota. Frequent environmental monitoring programs of desalination plants normally show that impacts are small, localized, and unimportant; however, significant effects have been detected in some cases. In these cases, effects can be mitigated by introducing devices that increase the mixing of effluent and surrounding seawater or/and by diluting the effluent before discharge.
\end{abstract}

Keywords: desalination impact, monitoring, mitigation

\section{Introduction}

Water is an essential element for life and thus a crucial natural resource; however, available freshwater resources have become increasingly limited in many parts of the world over the past few decades [1,2]. This is most notable in countries along the Arabian Gulf, the Mediterranean Sea, and the Red Sea because of high consumption and low precipitation $[3,4]$. Seawater desalination has been presented as a feasible alternative to cope with current water shortages. In recent years, the number of projected and constructed desalination plants has increased in these regions $[3,5,6]$ and in other countries such as China, the United States, Australia, and Chile [6].

Desalination is a process of removing dissolved salts and other minerals from seawater, brackish groundwater, or surface water. Several desalination technologies are in use and 
are based on thermal processes (e.g., multi-stage flash (MSF), multi-effect distillation (MED), and vapor compression) or membrane processes (e.g., electrodialysis (ED), reverse osmosis (RO), and nanofiltration). In most of these new facilities, RO is the preferred desalination technique primarily because it requires less space and energy and provides low-cost potable water compared with other techniques [2,7-9]. In RO, external pressure is applied to a concentrated solution, such as seawater or brackish water, to force water molecules through a semi-permeable membrane. This produces permeate comprising fresh water and a rejected concentrate [10]. The reject water, usually produced in huge volumes, is fundamentally brine (41-90 psu); concentrated by a factor that depends on the intake water salinity and on the water recovery or efficiency of the membranes in use [11]. Other chemicals, such as biocides, antiscalants, antifouling agents, coagulants, and antifoaming agents, used in desalination and maintenance processes may also accompany the brine effluent $[3,7,8,12,13]$.

Based on the volume of reject water, different methods can be considered for its disposal. These include discharge into the sea, deep wells, or evaporation ponds; co-disposal with industrial or wastewater effluents; or producing salt and other minerals as by-products [14-19]. Cost also plays a crucial role in selecting disposal methods; brine disposal into the sea is currently the least expensive approach $[3,8,16,17]$. However, discharging brine directly into the sea forms a high-density plume that sinks to the seafloor and extends horizontally, following the seafloor bathymetry and underwater currents [20]. Such a hypersaline water mass can negatively affect several benthic marine organisms that typically live in environments having stable salinity [3,9,21,22]. The most sensitive communities will be most affected, perhaps resulting in the total disappearance of these species in areas influenced by the brine. The magnitude of this impact depends on desalination plant and discharge system characteristics as well as the physical (i.e., bathymetry and hydrodynamics) and biological conditions of the receiving marine environment $[3,8,16,20]$.

The potential impact of desalination plants has increased in the last years [4,23-25]; however, most studies have not reported all the available information about the behavior of real hypersaline effluents and their effects on marine ecosystems. Moreover, available information is sometimes contradictory, outdated, or too local in its scope [26-37]. The deleterious environmental effects described in those studies should be detected in their first stages using rigorous monitoring programs, before marine communities are seriously affected [38,39]. Remedial and mitigation measures must be taken in case such effects are observed [40].

Regardless of the occasional perturbations, such as mechanical destruction and water turbidity, generated by the construction of intake or outfall structures, the main environmental impacts of desalination plant operation are caused by hypersaline effluent discharge [30,34,40,41]. These impacts will typically be prolonged in duration but can present some temporal fluctuations. Nevertheless, these effects depend on effluent composition derived from feed water quality as well as the desalination technology and chemical treatments employed [3].

The magnitude of these effects also depends on the sensitivity/tolerance of the affected marine communities, discharge location, and area under effluent influence. This area can be modified by modifying the effluent's dilution prior to discharge or by modifying the disposal device.

Herein, potential environmental impacts associated with brine discharge from desalination plants are considered and available information about minimizing their harmful effects is overviewed. 


\section{Factors affecting effluent composition}

Desalination plant waste effluents have varying compositions and characteristics. These factors depend on the raw water source, technology used, and chemicals added during seawater pre-treatment or formed as by-products of desalination activity [3].

\subsection{Feed water}

Desalination plant discharge is concentrated feed water; thus, its characteristics are primarily influenced by intake water composition. The raw water used in desalination plants can have various origins, with varying resultant properties. At present, desalination plants can use seawater, urban or industrial wastewater, or brackish water from aquifers. Moreover, seawater may be obtained from open near-surface intakes on the shoreline, from submerged intakes bringing in deeper water layers, or from intakes under the seafloor that draw seawater through permeable strata [41-44]. The latter intakes may be constructed as vertical or radial beach wells, infiltration galleries/beds, or horizontally drilled drains.

Using wastewater or brackish water as a feed intake produces reject water with lower salinity compared with that produced using seawater; however, it usually has a very high nutrient concentration. Unless these reject waters are treated to reduce their nutrient content, such as with biological filters, they pose environmental risks, particularly eutrophication. When industrial or urban wastewater is used as feed water, the desalination process yields reject water containing high concentrations of toxic substances. Discharging reject water with toxic substances into the marine environment could lead to substantial environmental problems [19].

Open intakes are the simplest way to provide sufficient seawater flow for large desalination plants; however, the presence of organic matter, microorganisms, and suspended solids requires employing aggressive pretreatment, adding chemical additives, and frequent cleaning of filters and membranes. If this intake option cannot be avoided, remedial strategies, such as using a screen or coarse filter, reducing intake water velocity, or placing the intake system at a certain depth beneath the water surface, should be used $[41,42]$.

Below-ground intakes naturally filter feed water, providing feed water with more constant and homogeneous physical and chemical characteristics and smaller amounts of organic matter and nutrients than open intakes. Consequently, to minimize the environmental impacts of brine discharges, obtaining seawater through permeable strata (i.e., beach wells, infiltration galleries, or directed drilling of horizontal drains; Fig. 1) is preferable. This is because such feed water is prefiltered, thereby optimizing pretreatment processes and reducing pollutant concentrations of the subsequent reject water $[8,42,45-47]$. These kind of intakes also reduce impingement and entrainment of marine organisms [3]. 


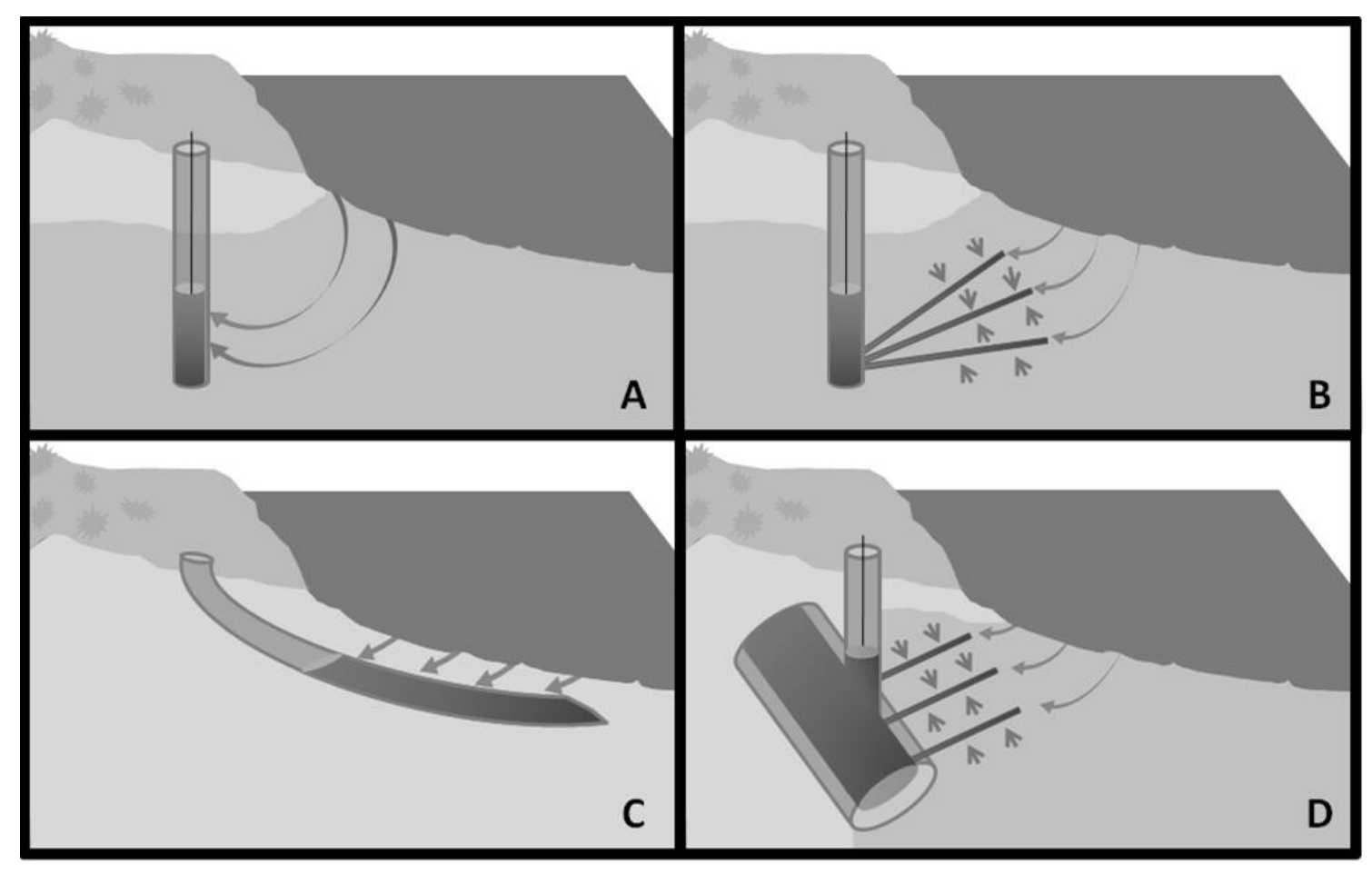

Fig. 1. Popular submerged intake systems: A) vertical beach wells, B) radial beach wells, C) horizontally drilled drains, and D) infiltration galleries (adapted from Missimer and Maliva [41]).

\subsection{Desalination technologies}

Brine discharge characteristics and composition also considerably differ depending on the technology employed by the desalination plants. Several available desalination techniques are most commonly based on thermal processes or the use of membranes [3]. Thermal techniques, such as MSF, MED, and vapor compression, remove salts by transforming water into steam; the steam is then condensed to fresh water. Membranebased techniques, including RO and ED, use membranes to separate salts from the feed water.

The type of desalination system used influences effluent composition. Thermal techniques produce reject water with slightly elevated salinity $(\approx 50 \mathrm{psu})$. However, as the temperature increases from $5^{\circ} \mathrm{C}$ to $15^{\circ} \mathrm{C}$, a neutral or buoyant plume is formed. This effluent also has a very low dissolved oxygen concentration and considerable quantities of copper due to heat exchanger corrosion [3,7]. Because of its surface dispersal, warm discharge from thermal desalination plants would mainly affect pelagic communities, although impacts on the benthic community have also been observed [26].

Concentrate discharges from RO plants are characterized by high salinities (65-90 psu), exhibiting slight temperature change relative to ambient values. These discharges form plumes that are generally denser than seawater that tend to sink and spread on the sea bottom [20] wherein they may affect benthic ecosystems [48]. However, this trend can vary seasonally. At the Alicante desalination plant during summer, maximum salinity was observed above the thermocline and not at the bottom because of the cold and dense water beneath the thermocline $[20,30]$. 


\subsection{Chemical treatments}

Concentrate discharges may also contain substances used during desalination processes, such as those used during pretreatment, cleaning of RO plant filters and membranes, or reducing foaming in distillation plants (Table 1).

Table 1. Common chemicals used during desalination processes.

\begin{tabular}{|c|c|c|}
\hline \multirow[t]{5}{*}{ Pretreatment } & Biocides & $\begin{array}{l}\text { Sodium hypochlorite }(\mathrm{NaOCl}) \text {, free chlorine, chlorine } \\
\text { dioxide, monochloramine }\left(\mathrm{NH}_{2} \mathrm{Cl}\right) \text {, ozone }\left(\mathrm{O}_{3}\right) \text {, } \\
\text { copper sulfate }\left(\mathrm{CuSO}_{4}\right)\end{array}$ \\
\hline & Dechlorination & Sodium bisulfite (SBS: $\mathrm{NaHSO}_{3}$ ) \\
\hline & $\begin{array}{l}\text { Coagulants or } \\
\text { flocculants }\end{array}$ & $\begin{array}{l}\text { Ferric chloride }\left(\mathrm{FeCl}_{3}\right) \text {, ferric sulfate }\left(\mathrm{FeSO}_{4}\right) \text {, } \\
\text { aluminum chloride }\left(\mathrm{AlCl}_{3}\right)\end{array}$ \\
\hline & Antiscalants & $\begin{array}{l}\text { Sulfuric acid }\left(\mathrm{H}_{2} \mathrm{SO}_{4}\right) \text {, phosphonates, polyphosphates } \\
\text { (sodium hexametaphosphate (SHMP: }\left(\mathrm{NaPO}_{3}\right)_{6} \text {, } \\
\text { diethylenetriamine pentamethylene phosphonic acid } \\
\left(\text { DTPMP: } \mathrm{C}_{9} \mathrm{H}_{21} \mathrm{~N}_{3} \mathrm{O}_{15} \mathrm{P}_{5} \mathrm{Na} \text { ) ), polyacrylic acid, }\right. \\
\text { polymaleic acid }\end{array}$ \\
\hline & Antifoaming & Polyethylene glycol, polypropylene glycol \\
\hline \multicolumn{2}{|c|}{$\begin{array}{l}\text { Cleaning of filters and } \\
\text { membranes }\end{array}$} & $\begin{array}{l}\text { Citric acid }\left(\mathrm{C}_{6} \mathrm{H}_{8} \mathrm{O}_{7}\right) \text {, sodium hydroxide }(\mathrm{NaOH}) \text {, } \\
\left.\text { ethylenediaminetetraacetic acid (EDTA: } \mathrm{C}_{10} \mathrm{H}_{6} \mathrm{~N}_{2} \mathrm{O}_{8}\right) \\
\mathrm{Na} \text { EDTA, sodium dodecylsulphate }\left(\mathrm{Na}_{4} \mathrm{DSS}\right) \text {, } \\
\text { hydrochloric acid }(\mathrm{HCl}) \text {, sodium dithionite }\left(\mathrm{Na}_{2} \mathrm{~S}_{2} \mathrm{O}_{4}\right) \text {, } \\
\left.\text { sodium metabisulfite (SMBS: } \mathrm{Na}_{2} \mathrm{~S}_{2} \mathrm{O}_{5}\right) \text {, sodium } \\
\text { polyphosphate }\left(\mathrm{NaPO}_{3}\right) \text {, phosphoric acid }\left(\mathrm{H}_{3} \mathrm{PO}_{4}\right)\end{array}$ \\
\hline
\end{tabular}

A wide range of chemicals is used in pretreatment, and chemical choices depend on water quality [49]. For example, chlorine is an effective biocide added to intake water in most desalination plants to control and reduce biofouling throughout the system [23]. In RO plants, chlorine would degrade the membranes; thus, it is neutralized before reaching the membranes [4,7]. However, in MED and MSF plants, chlorine can be directly discharged with desalination concentrate, acting as an unwelcome biocide in the marine environment and forming mutagenic compounds such as halogenated organic by-products $[3,23,50]$.

Chlorine is neutralized in RO plants using reducing agents such as sodium bisulfite (SBS: $\mathrm{NaHSO}_{3}$ ); however, a very high SBS dosage can reduce dissolved oxygen levels in the concentrate discharge [4,51]. Chlorine dioxide is also being used as a substitute for chlorine in RO plants because it acts with a shorter contact time and lower dosage and does not form halogenated compounds. Other chemicals are also used to control biofouling in RO plants, such as monochloramine $\left(\mathrm{NH}_{2} \mathrm{Cl}\right)$, ozone $\left(\mathrm{O}_{3}\right)$, and copper sulfate $\left(\mathrm{CuSO}_{4}\right)$. Additionally, non-chemical options, such as UV light (200-300-nm wavelength) or ultra- and micro-filtration prefiltration membranes, are available; however, none of these treatments has yet gained wide acceptance over chlorine use $[6,52,53]$.

Pretreatment also includes removing suspended material from the feed water to avoid damaging the membranes. This can be achieved via chemical treatment using ferric chloride $\left(\mathrm{FeCl}_{3}\right)$ and ferric sulfate $\left(\mathrm{FeSO}_{4}\right)$, which coagulates suspended particles. These materials are then easily retained in the filter beds [11], which are periodically backwashed to remove the coagulants employed and can discharge them (coagulants + 
retained materials) into the sea along with the concentrate [54]. These substances are not toxic to marine life [55] but can increase turbidity [6]. This mild impact can be minimized by correctly diluting the backwash effluent, discharging it in highly hydrodynamic areas, or disposing it as solid sludge in a landfill [3]. Low-pressure prefiltration membranes, an emerging technology, improve the coagulation process and reduce RO membrane cleaning frequency and replacement rates. However, such a pretreatment system has other periodic cleaning needs and thus does not completely remove the need to use chemicals [6].

Precipitation of salts and scale formation inside RO and distillation desalination plants must be also avoided because it can considerably reduce permeate flux. Membrane scaling is caused by feed waters supersaturated with inorganic compounds. Depending on the source water and desalination technology used, scales are often formed by calcium carbonate $\left(\mathrm{CaCO}_{3}\right)$, calcium sulfate $\left(\mathrm{CaSO}_{4}\right)$, magnesium hydroxide $\left(\mathrm{Mg}(\mathrm{OH})_{2}\right)$, and silica. Scaling can be generally controlled by treatment with acids, primarily sulfuric acid $\left(\mathrm{H}_{2} \mathrm{SO}_{4}\right)$, to reduce incoming seawater $\mathrm{pH}(6-7)$ or with scale inhibitors such as organic polymers, phosphonates, and polyphosphates [7]. $\mathrm{pH}$ reduction is not very strong ( $\mathrm{pH} 6-$ 7) and usually reaches ambient values $(\mathrm{pH} \mathrm{8.2)}$ at the effluent outfall; however, some scale-control additives can negatively affect the receiving environment. Among these additives, orthophosphates are the most environmentally important additives. This is particularly true for sodium hexametaphosphate (SHMP), which yields phosphorus. Phosphorus is an essential macro-nutrient directly available to marine primary producers, increasing their growth and potentially leading to eutrophication. Organic polymers, such as polyacrylic acid and polymaleic acid, and phosphonates are good alternatives to SHMP because they are not toxic to marine ecosystems.

Another conventional pretreatment step in MSF plants is controlling foaming to avoid contaminating produced water with salts [4]. Antifoaming agents, such as polyethylene glycol and polypropylene glycol, are added to feed water to disperse organic compounds that cause foam and reduce water surface tension. These substances are nontoxic, particularly at such low concentrations; therefore, they are discharged without any concerns [56].

Corrosion of equipment inside desalination plants can be problematic [57] because it may increase heavy metal concentrations (mainly copper, nickel, and iron) in the discharge to levels that are harmful to marine organisms. This problem is more acute in distillation plants, wherein high temperatures favor metal corrosion. In contrast, RO facilities operate at lower temperatures and are typically constructed from corrosion-resistant stainless steel $[23,57]$. Moreover, thermal plants use heat exchangers containing copper, which is toxic to algae and other marine organisms such as benthic invertebrates [26].

Despite feed water pretreatment, additional treatments are required to maintain desalination plant processes. To ensure smooth operation, filter beds and membranes in RO plants require periodic cleaning. The amount and type of cleaning solution depends on feed water quality, foulant type, membranes in use, and plant size [57]. Some most frequently used cleaning solutions include $\mathrm{NaOH}, \mathrm{Na}$ EDTA, Na-DSS, $\mathrm{HCl}, \mathrm{Na}_{2} \mathrm{~S}_{2} \mathrm{O}_{4}$, $\mathrm{H}_{3} \mathrm{PO}_{4}$, and $\mathrm{NH}_{2} \mathrm{SO}_{3} \mathrm{H}$. These cleaning solutions, which usually include detergents, biocides, organic matter, and acidic ( $\mathrm{pH} 2-3)$ or alkaline ( $\mathrm{pH} \mathrm{11-12)} \mathrm{cleaning} \mathrm{solutions,}$ are occasionally discharged. Maintenance cleaning of distillation plants is simpler and typically involves acid washing at $\mathrm{pH} 2$. Most of these chemical additives are not normally considered harmful to the marine environment; however, their residues, particularly those of biocides, should be diluted and neutralized before being discharged into the sea [3]. Without this dilution, some cleaning chemicals, such as sodium metabisulfite (SMBS: $\mathrm{Na}_{2} \mathrm{~S}_{2} \mathrm{O}_{5}$ ), can cause environmental problems [58]. 
In any case, when chemicals cannot be avoided, they need to be substituted with new "green" additives (i.e., nontoxic and rapidly biodegradable chemicals) $[59,60]$.

\section{Effects on marine communities in the discharge area}

Because RO discharges have higher density, they typically sink to the seafloor, thereby affecting benthic communities. In contrast, warm discharges from distillation plants may affect pelagic communities because of their surface dispersion. Although some organisms may tolerate environmental changes, others are highly sensitive. This implies that small changes in ambient conditions may lead to their death or regression [40]. Some affected organisms can escape the impact area, but benthic organisms fixed to the seafloor or those that cannot flee can die, thereby changing species composition and abundance in discharge site benthic communities [33,37]. In any case, brine discharge effects depend on location, affected marine organism tolerance, and the size of the area of the sea involved.

\subsection{Marine organism tolerance}

Marine organism tolerance is a critical point regarding effluent environmental impacts. Organisms must have a specific, and relatively constant, internal concentration of salts; however, this can be influenced by salt concentrations of surrounding media because of entry through semi-permeable membranes. Depending on their capacity for osmotic regulation, marine organisms generally have two possible strategies for coping with salinity changes. Osmoconformers organisms, such as echinoderms (Fig. 2) and most invertebrates, have a very low capacity to regulate internal osmotic concentration, which resembles their inhabited environment. Osmoconformers are thus very sensitive to minor environmental salinity changes. Fishes and most vertebrates are however osmoregulators; in other words, they can adjust their internal osmotic concentration using various strategies, such as accumulating organic salts within their tissues, incorporating large amounts of water, or excreting selected ions. Osmoregulators have different tolerances to salinity changes. Osmoregulation has a high energy cost, which is reflected in lower growth rates and higher mortalities of organisms when exposed to salinity levels outside their optimal tolerance ratio. 


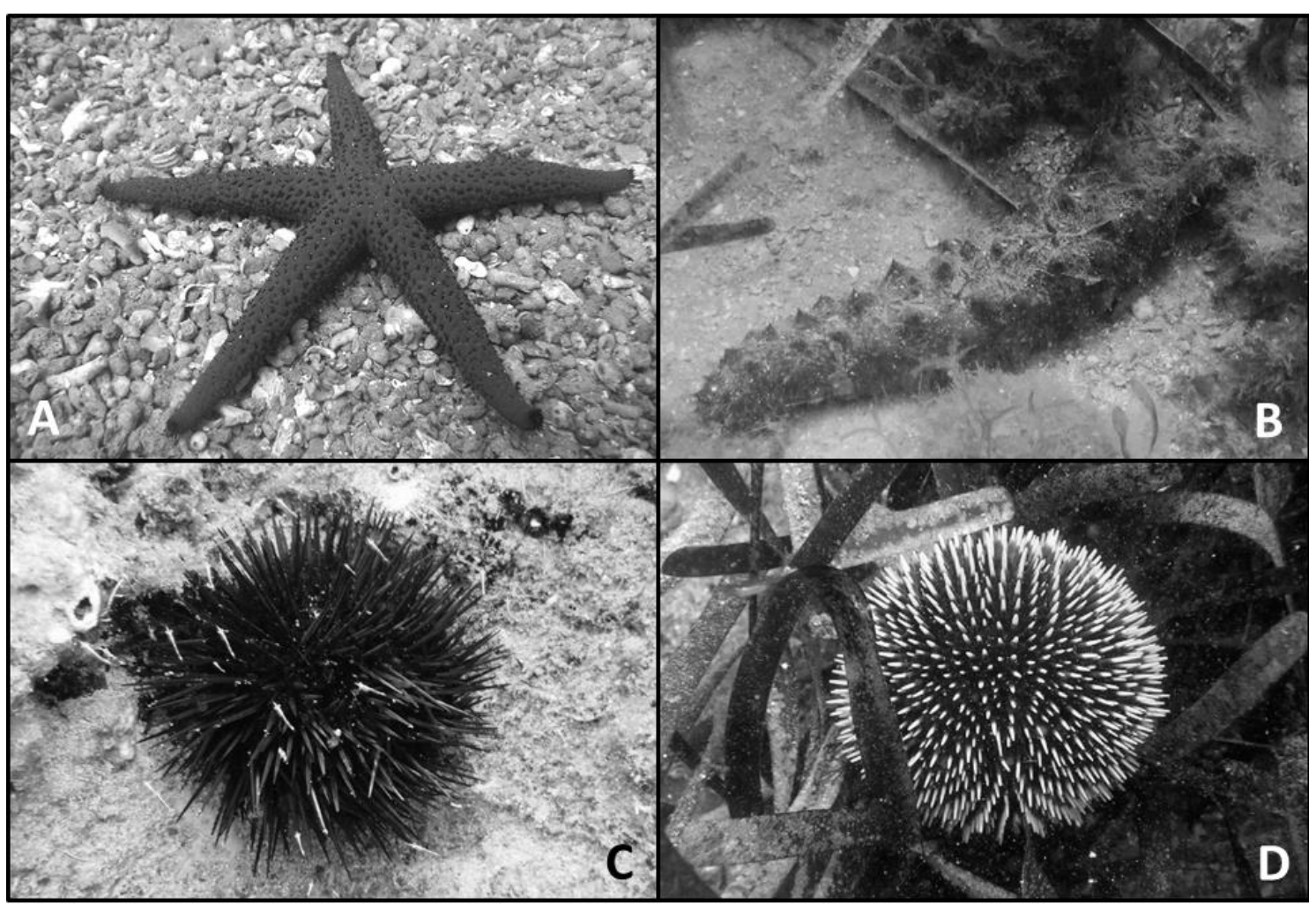

Fig. 2. Some echinoderm species: A) A sea star (Echinaster sepositus), B) a sea cucumber (Holothuria sp.), and sea urchins C) Paracentrotus lividus and D) Sphaerechinus granularis.

Some marine organisms can withstand small salinity variations or occasional exposure to extreme levels. However, extreme, abrupt, and persistent changes can result in physiological stress, causing mortality of less mobile organisms that cannot escape. Additionally, such salinity changes often occur simultaneously with changes in temperature, turbidity, or $\mathrm{pH}$, which can in turn alter the tolerance of marine species to salinity changes [61-63].

Consequently, an area influenced by a hypersaline discharge can have reduced biodiversity due to the disappearance of most sensitive species, thereby proliferating more tolerant species [34].

To minimize effects on marine biota, sensitive habitats and communities or zones with protected, endangered, or key species (such as seagrass meadows, maërl beds, coralligenous and coral reefs, and mangroves) must be avoided when possible. Hypersaline brines should be preferably discharge in areas with sandy seafloors without vegetation or localities that have already been degraded. If discharge in sensitive communities or ecologically important areas cannot be avoided, understanding the tolerance of key species to the increased salinity and establishing precautionary thresholds are crucial [48].

\subsection{Salinity tolerance thresholds}

The tolerance of key ecosystems to brine discharges must be studied. Such ecosystems are composed of endangered or protected habitat-forming species, and many other species are dependent on them for survival. Moreover, when these communities or species are 
widely distributed, they are ecologically important. Therefore, their tolerance to desalination effluent components, particularly high salt content, must be determined.

Ocean salinity varies within narrow margins; therefore, it has not been conventionally considered as a major factor affecting the abundance or distribution of marine species. Nevertheless, these margins can be wider in coastal waters, particularly in estuaries or coastal lagoons where salinity values show considerably more variation.

Therefore, the tolerance of most marine organisms to salinity changes is not well known. Most of the scarce published studies were carried out on species from estuaries and intertidal zones or those of commercial interest and generally under laboratory conditions. Moreover, most of this research refers to the tolerance to salinities lower than normal salinity. Effects of hypersalinity on strictly marine species have been scarcely reported. However, salinity tolerance of the seagrass Posidonia oceanica, has been reported. This is because it is a protected habitat-forming species with very slow growth, sensitivity to environmental changes, and is widely distributed in areas of the Mediterranean coast wherein water scarcity has led to the construction of large desalination plants. The tolerance was determined via field and laboratory experiments $[32,48,64,65]$, and a recommended threshold has been incorporated into the relevant environmental licenses and monitoring programs. Similar studies have been conducted on other seagrasses $[63,66,67]$.

Australia's natural variability of salinity in open waters ( 1 psu) has been used as a threshold to be maintained at a certain distance from the discharge $[68,69]$. Most marine organisms should be adapted to salinity changes of the same magnitude as natural changes [69].

\section{Reducing effects on marine communities}

\subsection{Effluent disposal}

Concentrated effluent from a desalination plant can be disposed in various ways [41,70]. Effluent is usually discharged directly at the shore or via a pipeline in coastal plants. Inland plants using brackish feed water cannot generally discharge effluent into the sea because of the distance involved. Brine from inland plants is thus discharged into deep wells or evaporation ponds. Other discharge options include treatment in wastewater plants, production of salt and other minerals, and obtaining a near-zero (n-ZLD) or zero liquid discharge (ZLD) [14-18].

Direct discharge into the sea is currently the most common and least expensive disposal method employed in coastal desalination plants. Brine can be discharged through a pipeline or directly at the shoreline; however, it should be optimized to ensure rapid mixing and dilution. Indeed, it is convenient to discharge brine in areas with mobile hydrodynamics, wherein more mixing can occur, rather than in closed areas with calm sea conditions.

\subsubsection{Direct discharge at the coastline}

Ocean brine disposal has long been recognized as the simplest and least expensive method and can usually be considered for small plants [8]. Brine can be directly discharged on the coastline or on existing infrastructure such as harbors or artificial channels. Nevertheless, even with satisfactory dilution most of the time, the discharge plume may reach a very large area on calm days. However, its extent may be considerably reduced through bypassing sea water, which is a technique that has been used for plants near 
sensitive ecosystems. In the Javea desalination plant (Alicante, Spain), a constant seawater-to-brine ratio of $4: 1$ is used to reduce discharge salinity below 44 psu [71]; a similar strategy has been used for the Alcudia plant (Balearic Islands, Spain) [72]. At the Alicante facility (Alicante, Spain), precise prior dilution depends on oceanographic conditions required to comply with environmental threshold limits [20]. When salinity at the $P$. oceanica meadow exceeds the established threshold, the seawater by-pass ratio increases. This usually happens during winter or spring, whereas the dilution remains lower during summer and autumn.

\subsubsection{Discharge via submarine pipelines into the sea}

Brine is commonly discharged at a distant offshore through submarine outfalls rather than direct outfall at the coastline. Brine is denser than seawater and thus tends to flow down to deeper areas; therefore, the outlet must be deeper than the plant's feed water intake to avoid backflow of discharge with feed water. If the brine is discharged at a greater depth, it will avoid fragile coastal communities or those with high environmental value. However, the possibilities of mixing are lower because of the more static hydrodynamic conditions. If brine is discharged at a greater depth, the outfall should terminate in one or more upward deflecting diffusers to maximize effluent mixing as this option reduces the area of negative influence [51,73-75]. Additionally, possible pipeline breaks due to storms or other events may affect shallower sensitive habitats and should thus be monitored [76].

In any case, adverse effects during outfall construction must be minimized by selecting an appropriate pipeline route and installing it with minimal disturbance to the marine environment. Some marine civil engineering methods have greater impact than others and should be selected based on the area's environmental sensitivity [70].

\subsection{Effluent dispersion}

Negative desalination activity impacts can be minimized by selecting an optimal concentrate disposal method and by suitable effluent mixing and dilution [8,77]. Artificial equipment, such as diffusers, and natural processes, such as the water column mixing process associated with certain local hydrodynamic conditions, can be applied [8].

The natural dispersion of effluent mainly depends on site-specific conditions such as bathymetry (slope of seafloor and water depth); geomorphology (bottom relief and roughness or rugosity); and hydrodynamics (waves, currents, and tides). Mixing behavior can also depend on disposal methods (e.g., using single outlet or multiport diffusers, effluent volume, flow rate, and discharge velocity) and concentrate properties (salinity, temperature, and density) [74,78]. However, some of these factors may vary seasonally, implying that brine mixing may be insufficient during some periods of the year. Therefore, selecting an appropriate discharge location would minimize environmental impacts by ensuring rapid dilution of the brine effluent.

The behavior of seawater RO desalination discharge follows the pattern of effluents that are denser than seawater. Mixing is optimal in the near-field region because of turbulence effects; however, the gravity-driven plume forms a layer with lower dilution, which spreads along the maximum downward sea-bottom gradient [20]. This is the far-field region, where effluent only mixes via advection and diffusion, implying that the area subjected to high salinities is small but that subjected to only a slight increase in salinity may be very large. Expansion of this plume considerably varies depending on discharge type and desalination plant production. Moreover, reject brine plume discharge and 
behavior may vary seasonally. For example, when studying discharge from the Alicante desalination plant, a summertime seasonal thermocline was detected at a depth of 12-15 $\mathrm{m}$. Thus, low-density brine remained in the middle of the water column because of the low temperature of water below the thermocline [30]. Strong thermoclines during summer can keep the hypersaline layer a certain height above the seabed, exposing it more to waves and currents and thus increasing mixing and dilution. Strong thermoclines also prevent benthic communities from being subjected to permanent high salinity.

In general, any mechanism that favors maximizing the mixing and dilution of the discharged concentrate will reduce its area of influence and higher salinity values, thus mitigating environmental impacts. Some mechanisms may require additional energy consumption (water pumping or jet speed) or use the discharge's own kinetic and potential energy to rapidly mix with seawater (diffusers or bottom roughness).

When a desalination plant utilizes surface discharges directly at the shoreline, the most hydrodynamic sites should be selected because waves and currents act dynamically and increase initial mixing of the effluent. To increase mixing, alteration of the sea bottom, such as adding artificial structures to augment bottom roughness and its generated turbulence, can be useful.

For underwater outfalls, dilution can be enhanced at the discharge outlet using diffusers. These simple devices increase brine exit velocity and increase near-field mixing. Diffuser effects mainly depend on diffuser design parameters such as angle of inclination, number of nozzles, and depth. Diffuser orientation to enhance mixing has been studied in detail, and optimal dilution has been observed for diffusers aligned at $30^{\circ}-45^{\circ}$ to the seafloor. This alignment causes the brine flow to follow an upward parabola, which considerably accelerates mixing with ambient seawater $[8,73,79]$.

The area of influence of the hypersaline plume can be reduced via prior dilution of the concentrate, i.e., bypassing seawater to reduce density differences between brine and seawater [20].

In addition to pre-dilution with seawater, brine can be combined with wastewater from treatment plants (lower salinity than seawater) or cooling water from power plants (higher temperature than seawater). Such combined effluents can form a surface discharge with a lower density than seawater, thereby preventing the effect on benthic organisms [80]. However, dilution with wastewater should not become a generalized practice as wastewater can be recycled and reutilized on land. Additionally, unexpected negative synergistic effects may also occur.

Scale factor is observed in the area affected by a concentrate discharge. Dilution is considerably rapid for small desalination plants, whereas high salinities from largevolume plants have greater expansion. Therefore, mixing potential must be oversized during the project's construction phase to allow for later plant enlargement. Dilution can thus be increased without interrupting production.

Computerized simulation models can be a good tool to predict discharge behavior. However, these models frequently provide more optimistic results than real-time observations. These models can be applied to compare different mixing scenarios to identify the most feasible discharge options and minimize environmental impacts [74].

\section{Monitoring programs}

Environmental impacts of brine discharges from desalination plants can be minimized by selecting appropriate discharge locations or mitigating possible effects by prior dilution of the effluent. A carefully designed monitoring program should also be established to assess brine plume distribution over time and its effects on the marine environment [81]. 
Monitoring programs repeatedly observe a system to detect changes [82,83]. These programs should be designed to reduce and identify disturbances in an ecosystem at an early stage. Thus, regular sampling must be performed over time with observations at multiple locations. Environmental monitoring usually focuses on data collected from biological or physical parameters considered as useful target indicators for assessing the studied impact. Acceptable ranges of variation for these parameters must also be established. A monitoring program must also demonstrate whether observed changes are produced by the activity itself or caused by natural variation or other impacts on the area. Environmental impact studies should initially establish a baseline before the operation of the desalination plant begins. These studies feature original or normal key species distributions and the abundance and composition of other marine biota to be used as a reference to detect future changes.

Environmental monitoring programs must evaluate the appropriateness of the forecasts of baseline studies and environmental licenses to protect natural ecosystems and introduce necessary changes to permits and plans to mitigate environmental impacts. To achieve these objectives, concentrate discharge quantity and quality, area of influence, and effects on marine biota must be controlled.

Concentrate discharge quantity is directly linked to plant production and should thus be routinely registered. Discharge composition is relatively constant and is characterized by high salinity; however, it may have other components to be quantified to detect nutrients and other biologically relevant substances. In particular, nutrient levels must be measured because high nutrient levels may be observed if the feed water intake is through beach wells or if phosphate-containing antiscalants are used. Organic matter amounts must be also monitored when open seawater intakes are used. Several concentrate samples may be taken through the year; however, a high sampling frequency is not necessary because organic composition is normally relatively constant. For thermal desalination plants, the presence of heavy metals, particularly copper, should also be monitored.

Furthermore, the effluent's temporal and spatial dispersion must be determined by measuring the physical seawater properties near desalination plants. Surveys typically use a grid of stations around the effluent discharges. The studied area's extent and grid spacing will depend on desalination plant production, discharge type, the receiving environment (bathymetry and hydrodynamic regimes), and predictive models used. Samplings require conductivity, temperature, and depth devices (CTDs) or other equipment that can obtain water column temperature, salinity, and density profiles. These instruments aid in delimiting the brine plume and its dilution throughout the area. Dispersion may change with plant production and oceanographic conditions; therefore, several surveys must be conducted throughout the year to include seasonal variability (e.g., varying winds, calms, breezes, and thermocline). At least two CTD sampling campaigns per year must be undertaken: one in summer, with calm sea conditions, which often yields a lower brine dilution, and the other at the end of winter, with stronger hydrodynamic conditions, which yields a higher brine dilution [32].

Once salinity thresholds to protect key communities have been established, a continuous salinity register may have to be maintained. Conductivity and temperature devices (CTs) with incorporated data loggers are moored near the seabed and used to simultaneously measure salinity and temperature with great accuracy at multiple locations. Locations for CTs can be selected based on the presence of biological communities of interest, such as the $P$. oceanica meadow, to monitor salinity changes that may affect this community in control localities or in protected areas [32].

Biota changes can be monitored by focusing on (1) key species that are usually ecologically important bioconstructors, such as seagrasses, kelp forests, and corals, and 
(2) bioindicator species that are sufficiently sensitive to be used as an early warning for mitigating effects caused by brine discharge [84]. The monitoring program aims to prove that the discharge does not affect key species communities. Key and bioindicator species must be sedentary because high-mobility species do not necessarily reflect local ecologically significant conditions. Indicator species should also have a broad distribution, be extensively studied, and be sensitive to environmental variations [85]. Echinoderms (Fig. 2) have proven to be good indicators for monitoring brine discharge effects [86,87]. Other organisms that have been used to monitor the brine discharge effects include polychaetes, amphipods, ascidians, and sipunculans [26,33,34,88,89].

After selecting bioindicator species, the correct experimental design is developed to deal with the natural spatial and temporal variability of these organisms and detect important effects. As previously mentioned, an optimal sampling design should commence before the brine discharge begins to establish a baseline. Once the desalination plant begins to operate, changes from the preliminary state can then be clearly detected. If the monitoring program starts when desalination discharge is already in progress, then asymmetrical designs can be used and effects can only be demonstrated by comparison with more than one control or reference sites (Fig. 3).

Monitoring studies involve repeated sampling over time. Sampling frequency depends on monitoring program objectives and must consider natural seasonal variability and desalination plant output. Sampling should also be replicated in space. Monitoring programs should produce statistically interpretable results; therefore, sampling designs must be well planned with sufficient replicates and controls, with three or more replicates (i.e., samples, quadrates, and transects) chosen at each locality. Asymmetrical designs with several control localities are necessary to avoid pseudoreplication [90]. Usually, to develop a beyond before-after-control-impact (Beyond BACI) design (Fig. 3) would be difficult because sampling must be conducted in different periods (Time $1,2, \ldots n$ ) and long before desalination plant discharge commences [90].

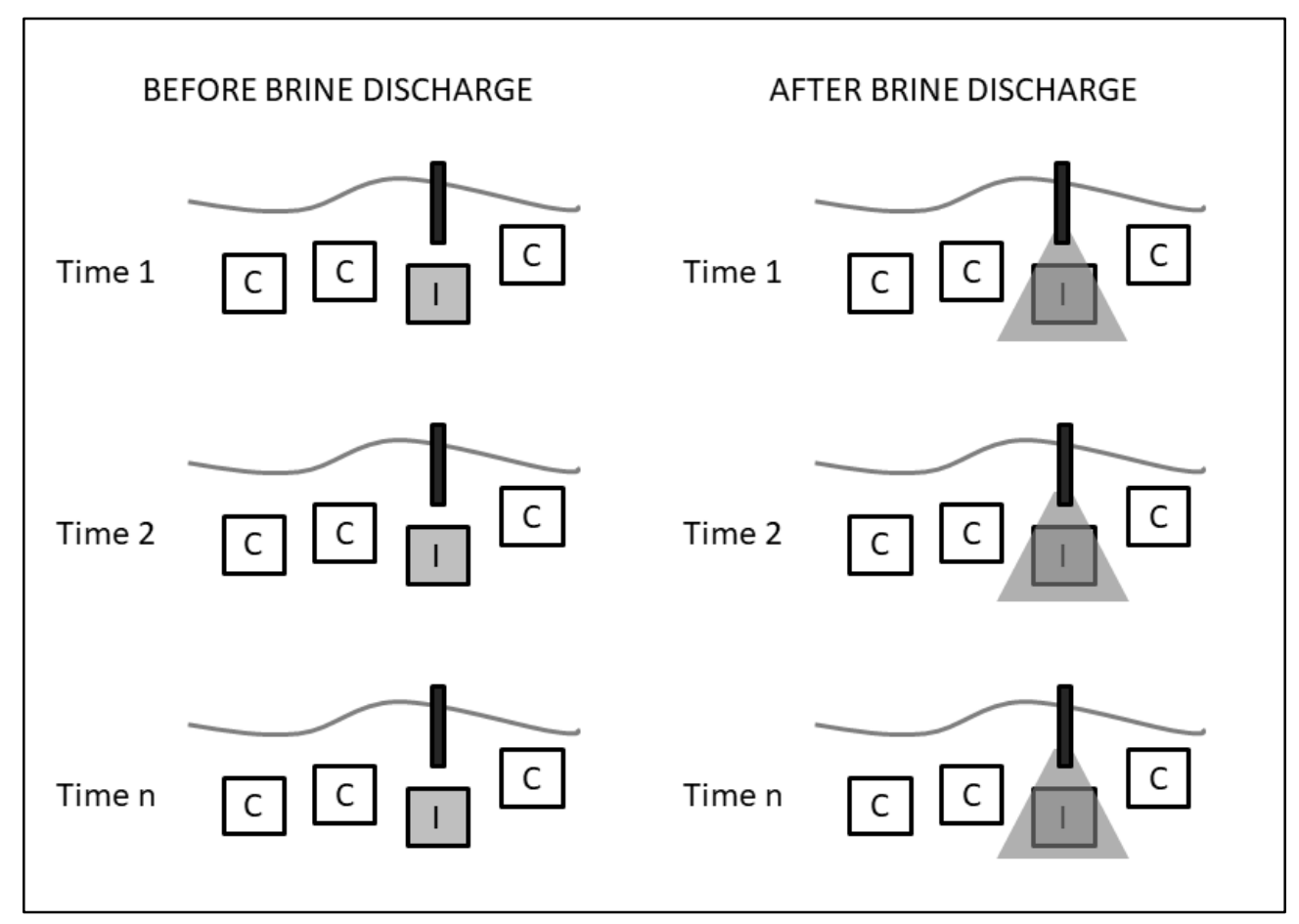

Fig. 3. Schematic of beyond before-after-control-impact (Beyond BACI) design $(\mathrm{C}=$ control localities and I = impact locality). 


\section{Conclusion}

Herein, the main environmental impacts of a desalination plant were described and approaches to minimize these impacts via appropriate planning and monitoring were discussed. These measures vary depending on plant size and type and the biological communities present in the discharge area.

To minimize the impact of desalination plants, a suitable location must be selected and brine dilution and mixing must be maximized. This may be achieved by diluting the concentrate with seawater prior to discharge, employing diffusers, or releasing the effluent in strongly hydrodynamic areas.

In any case, environmental impacts of desalination plants must be minimized. Environmental impacts should be detected in early stages before marine communities become seriously affected. Thus, monitoring programs must be carefully designed to determine the discharge behavior, assess potential adverse effects on the marine environment, and take appropriate measures when necessary.

\section{References}

[1] P.H. Gleick, Water in crisis: paths to sustainable water use, Ecol. Appl., 8 (1998) 571-579.

[2] M. Schiffler, Perspectives and challenges for desalination in the $21^{\text {st }}$ century, Desalination, 165 (2004) 1-9.

[3] S. Lattemann, T. Höpner, Seawater desalination. Impacts of brine and chemical discharges on the marine environment, Desalination Publications, L'Aquila, Italy,2003.

[4] S. Lattemann, T. Höpner, Environmental impact and impact assessment of seawater desalination, Desalination, 220 (2008) 1-15.

[5] D. Drami, Y.Z. Yacobi, N. Stambler, N. Kress, Seawater quality and microbial communities at a desalination plant marine outfall. A field study at the Israeli Mediterranean coast, Water Res., 45 (2011) 5449-5462.

[6] E. Jones, M. Qadir, M.T.H. van Vliet, V. Smakhtin, S. Kang, The state of desalination and brine production: A global outlook, Sci. Total Environ., 657 (2019) 1343-1356.

[7] A.J. Morton, I.K. Callister, N.M. Wade, Environmental impacts of seawater distillation and reverse osmosis processes, Desalination, 108 (1996) 1-10.

[8] R. Einav, K. Harussi, D. Perry, The footprint of the desalination processes on the environment, Desalination, 152 (2002) 141-154.

[9] A. Purnama, H.H. Al-Barwani, M. Al-Lawatia, Modelling dispersion of brine waste discharges from a coastal desalination plant, Desalination, 155 (2003) 41-47.

[10] C. Fritzmann, J. Löwenberg, T. Wintgens, T. Melin, State-of-the-art of reverse osmosis desalination, Desalination, 216 (2007) 1-76.

[11] J.J. Sadhwani, J.M. Veza, S. Carmelo, Case studies on environmental impact of seawater desalination, Desalination, 185 (2005) 1-8.

[12] T. Höpner, J. Windelberg, Elements of environmental impact studies on coastal desalination plants, Desalination, 108 (1996) 11-18.

[13] M. Abd El-Wahab, A. Zakria-Hamoda, Effect of desalination plants on the marine environment along the Red Sea, Egypt (Case study), Thalassas, 28 (2012) 27-36.

[14] P. Glueckstern, M. Priel, Optimized brackish water desalination plants with minimum impact on the environment, Desalination, 108 (1996) 19-26. 
[15] D. Squire, J. Murrer, P. Holden, C. Fitzpatrick, Disposal of reverse osmosis membrane concentrate, Desalination, 108 (1996) 143-147.

[16] M. Ahmed, W.H. Shayya, D. Hoey, A. Mahendran, R. Morris, J. Al-Handaly, Use of evaporation ponds for brine disposal in desalination plants, Desalination, 130 (2000) 155-168.

[17] M. Ahmed, W.H. Shayya, D. Hoey, J. Al-Handaly, Brine disposal from reverse osmosis desalination plants in Oman and the United Arab Emirates, Desalination, 133 (2001) 135-147.

[18] M. Ahmed, A. Arakel, D. Hoey, M.R. Thumarukudy, M.F.A. Goosen, M. Al-Haddabi, A. AlBelushi, Feasibility of salt production from inland RO desalination plant reject brine: a case study, Desalination, 158 (2003) 109-117.

[19] N. Voutchkov, Overview of seawater concentrate disposal alternatives, Desalination, 273 (2011) 205-219.

[20] Y. Fernández-Torquemada, J.M. González-Correa, A. Loya, L.M. Ferrero, M. Díaz-Valdés, J.L. Sánchez-Lizaso, Dispersion of brine discharge from seawater reverse osmosis desalination plants, Desalin. Water Treat., 5 (2009) 137-145.

[21] J.V. Del Bene, G. Jirka, J. Largier, Ocean brine disposal, Desalination, 97 (1994) 365-372.

[22] R. Einav, F. Lokiec, Environmental aspects of a desalination plant in Ashkelon, Desalination, 156 (2003) 79-85.

[23] G.A. Tuluram, M. Ilahee, Environmental concerns of desalinating seawater using reverse osmosis, J. Environ. Monitor., 9 (2007) 805-813.

[24] D.A. Roberts, E.L. Johnston, N.A. Knott, Impacts of desalination plant discharges on the marine environment: A critical review of published studies, Water Res., 44 (2010) 5117-5128.

[25] S. Lattemann, G. Amy, Marine monitoring surveys for desalination plants - a critical review, Desalin. Water. Treat., 51 (2013) 233-245.

[26] R.H. Chesher, Biological impact of a large-scale desalination plant at Key West, Florida, E.J. Ferguson, R.E. Johanes, Eds., Tropical marine pollution, Elsevier Scientific Publishing Company, Amsterdam, 1975, pp.99-181.

[27] D.A. Tomasko, N.J. Blake, C.W. Dye, M.A. Hammond, Effects of the disposal of reverse osmosis seawater desalination discharges on a seagrass meadow (Thalassia testudinum) offshore of Antigua, West Indies, Seagrasses: Monitoring, Ecology, Physiology and Management, 1999, pp. 99-112.

[28] L. Castriota, A.M. Beltrano, O. Giambalvo, P. Vivona, G. Sunseri, A one-year study of the effects of a hyperhaline discharge from a desalination plant on the zoobenthic communities in the Ustica Island Marine Reserve (Southern Tyrrhenian Sea), 36 CIESM, Monaco, 2001.

[29] J.L. Pérez Talavera, J.J. Quesada Ruiz, Identification of the mixing processes in brine discharges carried out in Barranco del Toro Beach, south of Gran Canaria (Canary Islands), Desalination, 139 (2001) 277-286.

[30] Y. Fernández-Torquemada, J.M. González-Correa, J.L. Sánchez-Lizaso, Preliminary results of the monitoring of the brine discharge produced by the SWRO desalination plant of Alicante (SE Spain), Desalination, 182 (2005) 395-402.

[31] N. Raventos, E. Macpherson, A. García-Rubiés, Effect of brine discharge from a desalination plant on macrobenthic communities in the NW Mediterranean, Mar. Environ. Res., 62 (2006) $1-14$.

[32] E. Gacia, O. Invers, M. Manzanera, E. Ballesteros, J. Romero, Impact of the brine from a desalination plant on a shallow seagrass (Posidonia oceanica) meadow, Estuar. Coast. Shelf Sci., 72 (2007) 579-590.

[33] Y. Del-Pilar-Ruso, J.A. de la Ossa Carretero, F. Giménez Casalduero, J.L. Sánchez Lizaso, Spatial and temporal changes in infaunal communities inhabiting soft-bottoms affected by brine discharge, Mar. Environ. Res., 64 (2007) 492-503.

[34] Y. Del-Pilar-Ruso, J.A. de la Ossa Carretero, F. Giménez Casalduero, J.L. Sánchez Lizaso, Effects of a brine discharge over soft bottom Polychaeta assemblage, Environ. Pollut., 156 (2008) 240-250. 
[35] Y. Del-Pilar-Ruso, J.A. de la Ossa Carretero, A. Loya-Fernández, L.M. Ferrero Vicente F. Giménez Casalduero, J.L. Sánchez Lizaso, Assessment of soft-bottom Polychaeta assemblage affected by a spatial confluence of impacts: Sewage and brine discharges, Mar. Pollut. Bull., 58 (2009) 765-786.

[36] R. Riera, F. Tuya, A. Sacramento, E. Ramos, M. Rodríguez, The effects of brine disposal on a subtidal meiofauna community, Estuar. Coast. Shelf Sci., 93 (2011) 359-365.

[37] R. Riera, F. Tuya, E. Ramos, M. Rodríguez, O. Monterroso, Variability of macrofaunal assemblages on the surroundings of a brine disposal, Desalination, 291 (2012) 94-100.

[38] Y. Fernández-Torquemada, J.L. Sánchez-Lizaso, Monitoring of brine discharges from seawater desalination plants in the Mediterranean, Int. J. Environ. Health, 1 (2007) 449- 461.

[39] J. Kämpf, Clarke, B., How robust is the Environmental Impact Assessment Process in South Australia? Behind the scenes of the Adelaide Seawater Desalination Project, Mar. Policy, 38 (2013) 500-506.

[40] Y. Del-Pilar-Ruso, E. Martínez-García, F. Giménez Casalduero, A. Loya Fernández, L. M. Ferrero Vicente, C. Marco Méndez, J.A. de la Ossa Carretero, J.L. Sánchez Lizaso, Benthic community recovery from brine impact after the implementation of mitigation measures, Water Res., 70 (2015) 325-336.

[41] T.M. Missimer, R.G. Maliva, Environmental issues in seawater reverse osmosis desalination: Intakes and outfall, Desalination, 434 (2018) 198-215.

[42] D. Gille, Seawater intakes for desalination plants, Desalination, 156 (2003) 249-256.

[43] M. Fariñas, L.A. López, New and innovative sea water intake system for the desalination plant at San Pedro del Pinatar, Desalination, 203 (2007) 199-217.

[44] T.M. Missimer, N. Ghaffour, A.H.A. Dehwah, R. Rachman, R.G. Maliva, G. Amy, Subsurface intakes for seawater reverse osmosis facilities: Capacity limitation, water quality improvement, and economics, Desalination, 322 (2013) 37-51.

[45] N. Voutchkov, SWRO desalination process: on the beach-seawater intakes, Filtr. Separat., 42 (2005) 24-27.

[46] T. Peters, D. Pintó, Sub-seabed drains provide intake plus pretreatment, Desalination and Water Reuse, 16 (2006) 23-27.

[47] T. Peters, D. Pintó, E. Pintó, Improved seawater intake and pre-treatment system based on Neodren technology, Desalination, 203 (2007) 134-140.

[48] J.L. Sánchez Lizaso, J. Romero, J.M. Ruiz, E. Gacia, J.L. Buceta, O. Invers, Y. FernándezTorquemada, J. Mas, A. Ruiz-Mateo, M. Manzanera, Salinity tolerance of the Mediterranean seagrass Posidonia oceanica: recommendations to minimize the impact of brine discharges from desalination plants, Desalination, 221 (2008) 602-607.

[49] A. Muñoz-Elguera, S.O. Pérez-Báez, Development of the most adequate pre-treatment for high capacity seawater desalination plants with open intake, Desalination, 184 (2005) 173183.

[50] V.D. Grebenyuk, A.A. Mazo, V.M. Linkov, New ecological problems in water desalination and water reuse, Desalination, 105 (1996) 175-183.

[51] E. Portillo, M. Ruiz de la Rosa, G. Louzara, J.M. Ruiz, L. Marin-Guirao, J. Quesada, J.C. González, F. Roque, N. González, H. Mendoza, Assessment of the abiotic and biotic effects of sodium metabisulphite pulses discharge from desalination plant chemical treatment on seagrass (Cymodocea nodosa) habitats in the Canary Islands, Mar. Pollut. Bull., 80 (2014) 222-233.

[52] A. Brehant, V. Bonnelye, M. Perez, Comparison of MF/UF pretreatment with conventional filtration prior to RO membranes for surface seawater desalination, Desalination, 144 (2002) 353-360.

[53] S. Jeong, Y. Park, S. Lee, J. Kim, K. Lee, J. Lee, H. Chon, Pre-treatment of SWRO pilot plant for desalination using submerged MF membrane process: Trouble shooting and optimization, Desalination, 279 (2011) 86-95. 
[54] A. Hashim, M. Hajjaj, Impact of desalination plants fluid effluents on the integrity of seawater, with the Arabian Gulf in perspective, Desalination, 182 (2005) 373-393.

[55] S.E. Pantell, Seawater desalination in California, California Coastal Commission, Report, 1993, Available at: www.coastal.ca.gov/web/desalrpt/dtitle.html.

[56] M.H. Auerbach, J.J. O'Neill, R.A. Reimer, S.W. Walinsky, Foam control additives in MSF desalination, Desalination, 38 (1981) 159-168.

[57] J.W. Odfield, B. Todd, Environmental aspects of corrosion in MSF and RO desalination plants, Desalination, 108 (1996) 7-36.

[58] T. Younos, Environmental issues of desalination, J. Contemp. Water Res. Educ., 132 (2005) 11-18

[59] A. Ketsetzi, A. Stathoulopolou, K.D. Demadis, Being green in chemical water treatment technologies: issues, challenges and developments, Desalination, 223 (2008) 487-493.

[60] H.Y. Li, W. Ma, L. Wang, R. Liu, L.S. Wei, Q. Wang, Inhibition of calcium and magnesiumcontaining scale by a new antiscalant polymer in laboratory tests and a field trial, Desalination, 196 (2006) 237-247.

[61] Y. Fernández Torquemada, J.L. Sánchez Lizaso, Efecto de una posible interacción entre el $\mathrm{pH}$ y la salinidad sobre el crecimiento de Posidonia oceanica (L.) Delile 1813, Boletín Inst. Esp. Oceanogr., 19 (2003) 247-252.

[62] Y. Fernández-Torquemada, M.J. Durako, J.L. Sánchez-Lizaso, Effects of salinity and possible interactions with temperature and $\mathrm{pH}$ on growth and photosynthesis of Halophila johnsonii Eiseman, Mar. Biol., 148 (2005) 251-260.

[63] Y. Fernández Torquemada, J.L. Sánchez Lizaso, Responses of two Mediterranean seagrasses to experimental changes in salinity, Hydrobiologia, 669 (2011) 21-33.

[64] Y. Fernández Torquemada, J.L. Sánchez Lizaso, Effects of salinity on leaf growth and survival of the Mediterranean seagrass Posidonia oceanica (L.) Delile, J. Exp. Mar. Bio. Ecol., 320 (2005) 57-63.

[65] J.M. Ruiz, L. Marín-Guirao, J.M. Sandoval-Gil, Responses of the Mediterranean seagrass Posidonia oceanica to in situ simulated salinity increase, Botanica Marina, 52 (2009) 459470.

[66] A. Garrote-Moreno, Y. Fernández-Torquemada, J.L. Sánchez-Lizaso, Salinity fluctuation of the brine discharge affects growth and survival of the seagrass Cymodocea nodosa, Mar. Pollut. Bull., 81 (2014) 61-68.

[67] M.L. Cambridge, A. Zavala-Perez, G. Cawthray G.A., Kendrick, Effects of high salinity from desalination brine on growth, photosynthesis, water relations and osmolyte concentrations of seagrass Posidonia australis, Mar. Pollut. Bull., 115 (2017) 252-260.

[68] D.I. Walker, J.L. Sánchez-Lizaso, Y. Fernández-Torquemada, Environmental risk assessment for the marine environment of the reverse osmosis seawater desalination plant in Binningup, Technical Report, 2008.

[69] G.F. Clark, N.A. Knott, B.M. Miller, B.P. Kelaher, M.A. Coleman, S. Ushiama, E.L. Johnston, First large-scale ecological impact study of desalination outfall reveals trade-offs in effects of hypersalinity and hydrodynamics, Water Res., 145 (2018) 757-768.

[70] T. Peters, D. Pintó, Seawater intake and pre-treatment/brine discharge - environmental issues, Desalination, 221 (2008) 576-584.

[71] J.J. Malfeito, J. Diaz-Caneja, M. Fariñas, Y. Fernández- Torquemada, J.M. González Correa, A. Carratala-Giménez, J.L. Sánchez Lizaso, Brine discharge from the Javea desalination plant, Desalination, 185 (2005) 87-94.

[72] D. Zarzo, C. García, J.L. Sánchez Lizaso, S. Deudero, A. Box, Environmental protection strategies in the Bahia de Alcudia project (Spain), Desalination for the environment: Clean water and energy, Baden Baden, 2009.

[73] T. Bleninger, G.H. Jirka, Modelling and environmentally sound management of brine discharges from desalination plants, Desalination, 221 (2008) 585-597.

[74] A. Loya-Fernández, L.M. Ferrero-Vicente, C. Marco-Méndez, E. Martínez-García, J. Zubcoff, 
J.L. Sánchez-Lizaso, Comparing four mixing zone models with brine discharge measurements from a reverse osmosis desalination plant in Spain, Desalination, 286 (2012) 217-224.

[75] E. Portillo, G. Louzara, M. Ruiz de la Rosa, J. Quesada, J.C. Gonzalez, F. Roque, M. Antequera, H. Mendoza, Venturi diffusers as enhancing devices for the dilution process in desalination plant brine discharges, Desalin. Water Treat., (2012) 1-18.

[76] J.L. Sánchez-Lizaso, Programa de vigilancia ambiental y reducción de los impactos ambientales de la desalación, IX Congreso Internacional AEDyR, Madrid, 2012.

[77] T. Höpner, A procedure for environmental impact assessments (EIA) for seawater desalination plants, Desalination, 124 (1999) 1-12.

[78] A. Loya-Fernández, L.M. Ferrero-Vicente, C. Marco-Méndez, E. Martínez-García, J.J. Zubcoff-Vallejo, J.L. Sánchez-Lizaso, Quantifying the efficiency of a mono-port diffuser in the dispersion of brine discharges, Desalination, 431 (2018) 27-34.

[79] I. Alameddine, M. El-Fadel, Brine discharge from desalination plants: a modelling approach to an optimized outfall design, Desalination, 214 (2007) 241-260.

[80] T. Bleninger, G.H. Jirka, Environmental planning, prediction and management of brine discharges from desalination plants, Final report MEDRC Series of R\&D Reports, 2010, Available

at: http://citeseerx.ist.psu.edu/viewdoc/download?doi=10.1.1.470.6450\&rep=rep1\&type=pdf.

[81] S.A. Jenkins, J.D. Paduan, P.J.W. Roberts, D. Schlenk, J.S. Weis, Management of brine discharges to coastal waters recommendations of a science advisory panel, Technical Report 694, California Water Resources Board, California, USA, 2012, Available at: https://www.waterboards.ca.gov/water_issues/programs/ocean/desalination/docs/dpr051812. pdf.

[82] M. Kingsford, C. Battershill, Studying temperate marine environments: a handbook for ecologists, Canterbury University Press, 1998.

[83] F.T. Short, L.J. McKenzie, R.G. Coles, K.P. Vidler, SeagrassNet manual for scientific monitoring of seagrass habitat (QDPI, QFS, Cairns), 2006, Available at: http://www.seagrassnet.org/sites/default/files/SeagrassNet_Manual_2006_Worldwide.pdf.

[84] J.S. Chang, Understanding the role of ecological indicator use in assessing the effects of desalination plants, Desalination, 365 (2015) 416-433.

[85] S. Molfetas, P. Blandin, Quelques éléments de réflexion sur la notion d'indicateur écologique, in Ecologie appliquée-Indicateurs biologiques et techniques d'études, Journées d'étude de l'association française des ingénieurs écologues, Grenoble 1981, pp. 167-173.

[86] Y. Fernández-Torquemada, J.M. González-Correa, J.L. Sánchez-Lizaso, Echinoderms as indicators of brine discharge impacts, Desalin. Water Treat., 51 (2013) 567-573.

[87] J.A. de-la-Ossa-Carretero, Y. Del-Pilar-Ruso, A. Loya-Fernández, LM. Ferrero-Vicente, C. Marco-Méndez, E. Martínez-García, F. Giménez-Casalduero, J.L. Sánchez-Lizaso, Bioindicators as metrics for environmental monitoring of desalination plant discharges, Mar. Pollut. Bull., 103 (2016) 313-318.

[88] J.A. de-la-Ossa-Carretero, Y. Del-Pilar-Ruso, A. Loya-Fernández, LM. Ferrero-Vicente, C. Marco-Méndez, E. Martínez-García, J.L. Sánchez-Lizaso, Response of amphipod assemblages to desalination brine discharge: Impact and recovery, Estuar. Coast. Shelf Sci., 172 (2016) 13-23.

[89] L.M. Ferrero-Vicente, A. Loya-Fernández, C. Marco-Méndez, E. Martínez-García, J.L. Sánchez-Lizaso, Soft-bottom sipunculans from San Pedro del Pinatar (Western Mediterranean): influence of anthropogenic impacts and sediment characteristics on their distribution, Anim. Biodiv. Conserv., 34 (2011) 101-111.

[90] A.J. Underwood, Experiments in Ecology. Their logical design and interpretation using analysis of variance, Cambridge University Press, Cambridge, 1997. 